Revista de Economia Política, vol. 34, n 4 (137), pp. 638-655, outubro-dezembro/2014

\title{
Crise global, mudanças geopolíticas e inserção do Brasil
}

\author{
BERNARDO CAMPOLINA \\ CLÉLIO CAMPOLINA DINIZ*
}

Global crises, geopolitical changes and insertion of Brazil. This paper has as its purpose to analyze the insertion of Brazil in the international economic order, considering the fundaments of the world power, the global crisis, the geopolitical changes and their consequences on the global order. The text attempts to present the advantages and structural challenges for an adequate international insertion of technology are the key elements in a process of economic and social innovation whose goals are to build a richer society, more just and compassionate, and environmentally sustainable.

Keywords: global Brazil in an environment of increasing international integration of production; defend the idea that education, science and crisis; geopolitical change; Brazil's international insertion.

JEL Classification: F01; F02; F5.

\section{A ESTRUTURAÇÃO DO PODER MUNDIAL E A CRISE DOS SISTEMAS CENTRAIS}

Uma das mais acreditadas análises teóricas dos fundamentos do poder mundial está baseada na articulação entre o poder militar e o domínio do território e deu origem à Geografia Política ou Geopolítica, onde são articulados os elementos relativos ao poder e ao território (Ratzel, 1890, apud Morais, 1990; Mackinder, 1904, 1943; Spykman, 1953). Mais tarde, Strange $(1988,1996)$ demonstrou que a força dos países na estrutura mundial de poder decorre da união dos poderes mi-

\footnotetext{
* Respectivamente, Professor adjunto do Departamento do CEDEPLAR/UFMG. E-mail: bcampolina@ cedeplar.ufmg.br; Professor titular aposentado do CEDEPLAR/ UFMG, Ministro da Ciência, Tecnologia e Inovação. E-mail: ministro@mct.gov.br. Submetido: 20/Agosto/2013; Aprovado: 10/janeiro/2014.
} 
litar, econômico, monetário e científico. A autora identifica duas formas principais de poder: poder estrutural e poder relacional. $\mathrm{Na}$ linha do segundo, Nye desenvolveu a análise de "soft Power".

O avanço teórico recente da economia política internacional vem introduzindo novos elementos para a compreensão da estrutura de poder mundial, em especial dos novos atores capazes de criar poder, exclusividade até então restrita aos Estados Nacionais. Entre esses atores destacam-se as empresas multinacionais, os cartéis (a exemplo da OPEP), as ONGs e os movimentos sociais. Com a crise internacional de 2008, a atuação de algumas dessas organizações ampliaram suas influências, a exemplo do poder crescente das agências de classificação de risco e das grandes empresas de contabilidade.

O cenário contemporâneo é de grandes mudanças na estrutura do sistema de poder mundial. Destacam-se os efeitos contraditórios do crescimento e da integração mundial na chamada "Era da Globalização"; as crises globais dos sistemas capitalista e socialista centrais; a emergência econômica de novos países, com destaque para a China; as aceleradas mudanças tecnológicas, e os novos e sofisticados recursos militares. Esses elementos terão fortes implicações na articulação do sistema de poder mundial e da posição relativa do Brasil, objetos da reflexão desenvolvida no presente trabalho.

$\mathrm{O}$ início do século XX foi marcado por uma sequência de grandes crises de dimensão ou implicações mundiais, com destaque para a I Guerra Mundial, a Revolução Russa, a Crise de 1929 e II Guerra Mundial (Hobsbawm, 1995). No pós-II Guerra, o mundo foi dividido em dois grandes blocos de poder. O bloco Ocidental ou capitalista, capitaneado pelos Estados Unidos, cuja aliança militar se consolidou com a criação da OTAN (Organização do Tratado do Atlântico Norte), em 1948. Sua governança global se estabeleceu a partir do acordo de Bretton Woods e da criação do FMI, BIRD e GATT. O bloco Oriental ou socialista, sob liderança da Rússia, cujo acordo militar de defesa se estabeleceu por meio do Pacto de Varsóvia, em 1955 e o mercado comum através do COMECOM. Dessa estrutura bipolar decorreu a "guerra fria". Foi criada a ONU em 1948, que funcionou como elo entre os dois sistemas, estabelecendo um espaço para negociações e evitando a ruptura total e uma nova guerra mundial.

Feita essa nova concertação da governança global, o capitalismo foi fortalecido, estabelecendo os padrões americanos de produção e consumo como norteadores para o resto do sistema capitalista e propiciando, ao mesmo tempo, o aumento dos fluxos de investimento direto estrangeiro articulado com a expansão e generalização das empresas multinacionais. Essa expansão foi, em grande medida, conduzida e estimulada pela atuação dos próprios Estados, na chamada era keynesiana (Bleaney, 1985). Além do apoio americano à recuperação de uma Europa devastada pela guerra, foram abertos os mercados às empresas japonesas e, posteriormente, coreanas e taiwanesas, em uma estratégia de defesa geopolítica do capitalismo e de contenção do avanço socialista. O resultado foi um período de ampla expansão do sistema capitalista - sob a liderança dos Estados Unidos, acompanhados pela Europa Ocidental, pelo Japão e pelas economias de mercado periféri- 
cas - o qual ficou conhecido na literatura como "Anos Dourados" ou "30 Gloriosos Anos" (Hobsbawm, 1994; Friden, 2006).

Paralelamente, o sistema socialista foi sendo ampliado e fortalecido, sob a liderança da União Soviética. Essa liderança foi ampliada durante a II Guerra pela ocupação e dominação de vários países do Leste Europeu, formando um bloco dominado e defendido pela Rússia em uma linha que se estendia do Mar Báltico ao Mar Adriático, que Churchill denominou de "cortina de ferro" (Churchill, 1946). A expansão socialista alcançou outras regiões, com as revoluções chinesa e cubana; com a guerra e posterior divisão da Coreia, e com as lutas no Sudeste Asiático, especialmente em Laos, Camboja e Vietnã, chegando à eleição livre de um presidente socialista no Chile - Salvador Allende.

O resultado do fortalecimento dos dois blocos gerou disputa e tensão, com ameaças mútuas, mas não efetivadas. Os avanços tecnológicos de ambos os lados levaram a uma corrida armamentista sem precedentes, com poder atômico de destruição em massa o que, de certa forma, impediu sua concretização - por isso o período ficou conhecido como de "guerra fria".

No entanto, a estrutura de poder montada durante a era stalinista, muito eficiente durante a II Guerra Mundial, começou a mostrar suas inconsistências logo após o fim do conflito mundial, acelerado com a morte e sucessões de Stalin. As crises econômica e política da União Soviética levaram ao seu desmoronamento, muito bem simbolizado pela queda do muro de Berlim e a reconstituição de 15 Estados Nacionais, seguidos por depressão econômica em toda a região.

O mesmo tempo em que se gestavam e desenvolviam as crises nos sistemas centrais (socialismo e capitalismo), as periferias dos mesmos passaram a assumir novos papéis, indicando alterações na geografia econômica e na geografia política mundiais, com destaque para China, Índia e Brasil, além do ressurgimento da Rússia.

\section{MUDANÇAS NA GEOPOLÍTICA MUNDIAL}

Tomado o período 2000-2011, dois fatos complementares se destacam. O primeiro é a perda de peso relativo na produção e nas exportações do capitalismo central, vale dizer, dos Estados Unidos, da União Europeia e do Japão, para outros países e regiões do globo. O segundo é a ampliação do peso do sistema até então periférico, não só dos denominados BRICS (Brasil, Rússia, Índia, China e África do Sul), por sua maior escala, mas também de vários outros países, especialmente dos novos membros do G20. Essas mudanças indicam alterações na geografia econômica e, também, na geografia política, com consequências na ordem global.

Tendo como ponto de partida o ano 2000, o capitalismo central, representado pelos Estados Unidos, União Europeia e Japão, com apenas 11\% da área e 13\% da população mundiais, respondia por $70 \%$ do PIB e $55 \%$ das exportações globais. Entre 2000 e 2011 essas participações caíram, respectivamente, para $65 \%$ e $45 \%$ (Tabela 1). Enquanto isso, toda a periferia teve sua participação aumentada, ampliando seu poder na governança global, refletido pela criação do G20. Por outro 
lado, isso ilustra uma contradição com a institucionalidade da governança global que continua sob o comando dos países centrais, a exemplo do FMI, do Banco Mundial e do Conselho de Segurança da ONU.

Os destaques das mudanças no peso econômico mundial são a China, a Índia e o Brasil, além dos demais novos membros do G20 (Rússia, África do Sul, Argentina, México, Turquia, Coreia do Sul, Arábia Saudita, Malásia e Austrália). A este respeito, Arrighi (2010) argumenta que o centro hegemônico do sistema mundial estaria se deslocando do Ocidente para o Oriente.

Tabela 1: Continentes e Países Selecionados: Área, População, PIB e Exportação, 2000 e 2011 (US\$ 2000) $)^{1}$

\begin{tabular}{|c|c|c|c|c|c|c|c|c|c|c|c|c|}
\hline \multirow{2}{*}{ Continentes e Paises } & \multicolumn{2}{|c|}{ Área } & \multicolumn{2}{|c|}{$\begin{array}{c}\text { População } \\
2011\end{array}$} & \multicolumn{4}{|c|}{ PIB } & \multicolumn{4}{|c|}{ Exportação } \\
\hline & Mil Km² & $\%$ & Milhões & $\%$ & *US\$ Tri. & $\%$ & *USs Tri. & $\%$ & *USS Tri. & $\%$ & *US\$ Tri. & $\%$ \\
\hline A. do Norte & 20227 & 15.1 & 346.1 & 5.0 & 10.6 & 32.9 & 12.6 & 29.7 & 1.4 & 17.8 & 2.0 & 13.9 \\
\hline EUA & 9832 & 7.3 & 311.6 & 4.5 & 9.9 & 30.6 & 11.7 & 27.6 & 1.1 & 13.7 & 1.6 & 11.6 \\
\hline Argentina & 2780 & 2.1 & 40.8 & 0.6 & 0.3 & 0.9 & 0.5 & 1.1 & 0.0 & 0.4 & 0.1 & 0.4 \\
\hline Brasil & 8515 & 6.3 & 196.7 & 2.8 & 0.6 & 2.0 & 0.9 & 2.2 & 0.1 & 0.8 & 0.1 & 0.9 \\
\hline México & 1964 & 1.5 & 114.8 & 1.6 & 0.6 & 1.8 & 0.7 & 1.7 & 0.2 & 2.3 & 0.3 & 2.0 \\
\hline Ásia & 31959 & 23.8 & 4186.5 & 60.0 & 8.9 & 27.4 & 13.5 & 31.6 & 2.1 & 26.8 & 5.0 & 35.4 \\
\hline China & 9600 & 7.1 & 1344.1 & 19.3 & 1.2 & 3.7 & 3.5 & 8.3 & 0.3 & 3.5 & 1.6 & 11.3 \\
\hline Oceania & 8561 & 6.4 & 37.1 & 0.5 & 0.5 & 1.5 & 0.6 & 1.5 & 0.1 & 1.3 & 0.1 & 0.9 \\
\hline União Europeia & 4329 & 3.2 & 487.0 & 7.0 & 8.1 & 25.0 & 9.4 & 22.2 & 2.8 & 34.8 & 3.9 & 27.7 \\
\hline Alemanha & 357 & 0.3 & 81.7 & 1.2 & 1.9 & 5.8 & 2.1 & 5.0 & 0.6 & 7.9 & 1.1 & 8.1 \\
\hline Resto da Europa & 18743 & 14.0 & 254.2 & 3.6 & 1.2 & 3.7 & 1.5 & 3.6 & 0.6 & 7.8 & 0.9 & 6.6 \\
\hline Russia & 17098 & 12.7 & 141.9 & 2.0 & 0.3 & 0.8 & 0.4 & 1.0 & 0.1 & 1.4 & 0.2 & 1.5 \\
\hline Mundo & 134269 & 100.0 & 6973.7 & 100.0 & 32.3 & 100.0 & 42.6 & 100.0 & 8.0 & 100.0 & 14.1 & 100.0 \\
\hline
\end{tabular}

Fonte: Banco Mundial - Acesso em Março 2013. *Valores Constantes 2000.

Observado o comportamento do conjunto de países que compõem o G20, as mudanças no cenário global ficam claras. Ainda no cenário das mudanças mundiais, há que considerar o novo papel da África. Com área geográfica de 30 milhões de $\mathrm{km}^{2}$, população de mais de 1 bilhão de habitantes e abundância de terras e matérias-primas, a África se transformou, nos últimos anos, em uma nova fronteira cobiçada pelas potências emergentes, como a China, ávida por alimentos e matérias-primas. O volume de investimentos estrangeiros que vêm sendo feitos no con-

\footnotetext{
${ }^{1} \mathrm{~A}$ instabilidade nas paridades cambiais entre as moedas dificulta as comparações internacionais ao se fazer a conversão em uma única moeda de referência. Estamos utilizando dólares constantes à preços do ano 2000 com base na Paridade do Poder de Compra (PPC). Os dados estão disponíveis em http:// data.worldbank.org/indicator/NY.GDP.MKTP.KD. No pós-crise de 2008 o dólar sofreu uma forte desvalorização, o que fez com que o Produto Interno Bruto da maioria dos países aumentasse. Nos últimos meses essa tendência está se invertendo, com efeito inverso. Para uma análise da complexidade do fenômeno e um discussão sobre o caso do Brasil veja, entre outros, Krugman, P. e Taylor, L. (1978), Thirlwall, A. P. (1979); Rodrik, D., (2007); Missio, Oreiro e Jayme Jr. (2010); Ferrari, Freitas e Barbosa Filho (2013).
} 
tinente e as novas institucionalidades surgidas após os movimentos de independência e os processos de descolonização indicam que o continente africano terá nova posição no cenário econômico e político mundial.

Gráfico 1: G20: Participação relativa no PIB Mundial, em 2000 e 2011

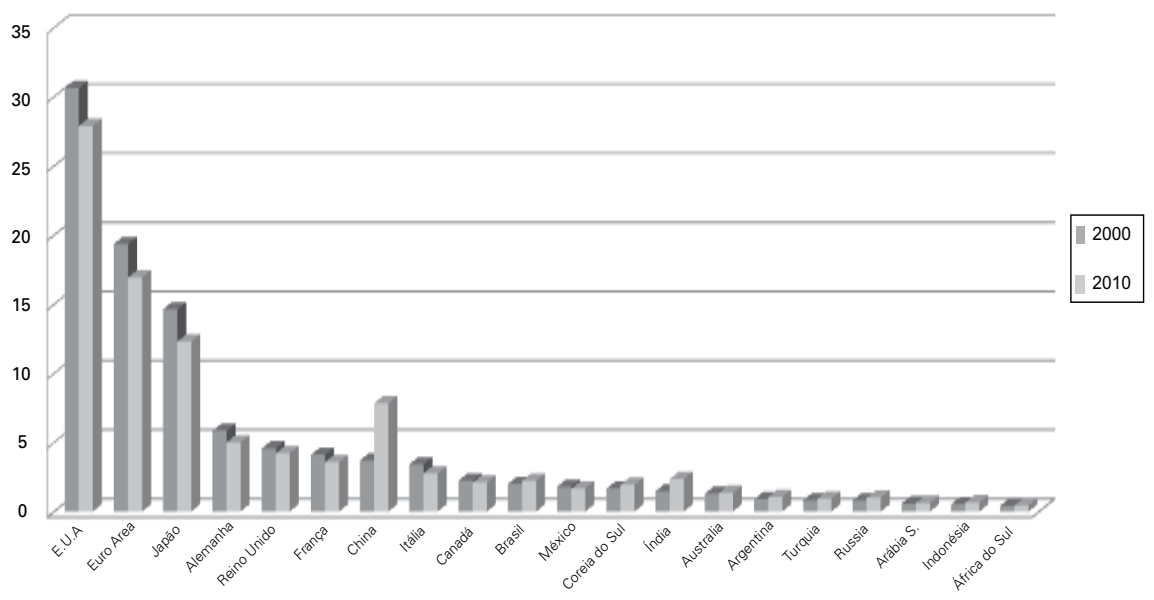

Gráfico 2: G20: Participação relativa nas Exportações Mundiais, 2000 e 2011

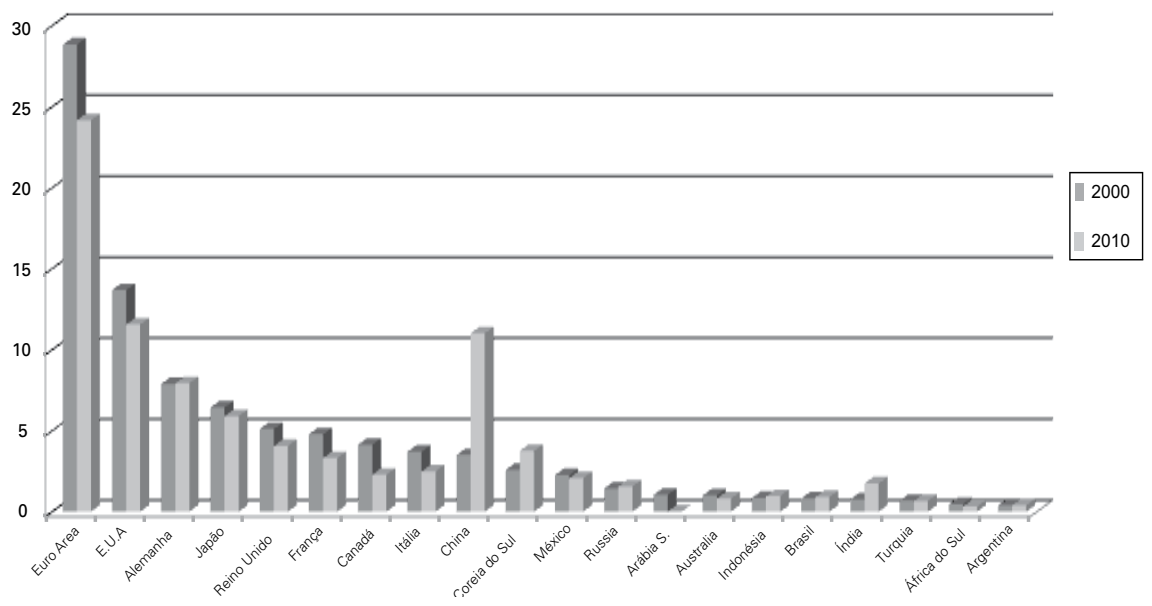

A continuidade desse processo de transformação não será simples. As forças econômica, política, cultural, científica e tecnológica do capitalismo central funcionarão como fortes restrições às mudanças. Nesse sentido, as recuperações recentes das economias americana e japonesa ilustram essas forças, embora a Europa ainda se encontre em grandes dificuldades econômicas. Adicionalmente, há que ressaltar o poder militar e os avanços tecnológicos e, mais ainda, a capacidade do sistema capitalista central, especialmente dos Estados Unidos, em exercê-lo, colocando novos desafios para a ordem mundial. 
No entanto, a capacidade científica e tecnológica de um conjunto de outros países vem se ampliando de forma significativa nos últimos anos. Indicadores da produção científica, medidos através do número de artigos indexados e publicados nos maiores periódicos internacionais, demonstram a ascensão de países como China, Índia e Brasil. Igualmente, o número de patentes produzidas e depositadas pelos países periféricos em seus próprios domínios legais e nos grandes centros internacionais (Estados Unidos e Europa) também vem se ampliando. Esses elementos poderão se traduzir em avanço relativo da periferia, beneficiados pelas vantagens decorrentes do atraso (late comer), como sugerem vários autores na linha do catching up, do forging ahead e do leap forging (Freeman, Perez \& Soete, 1988).

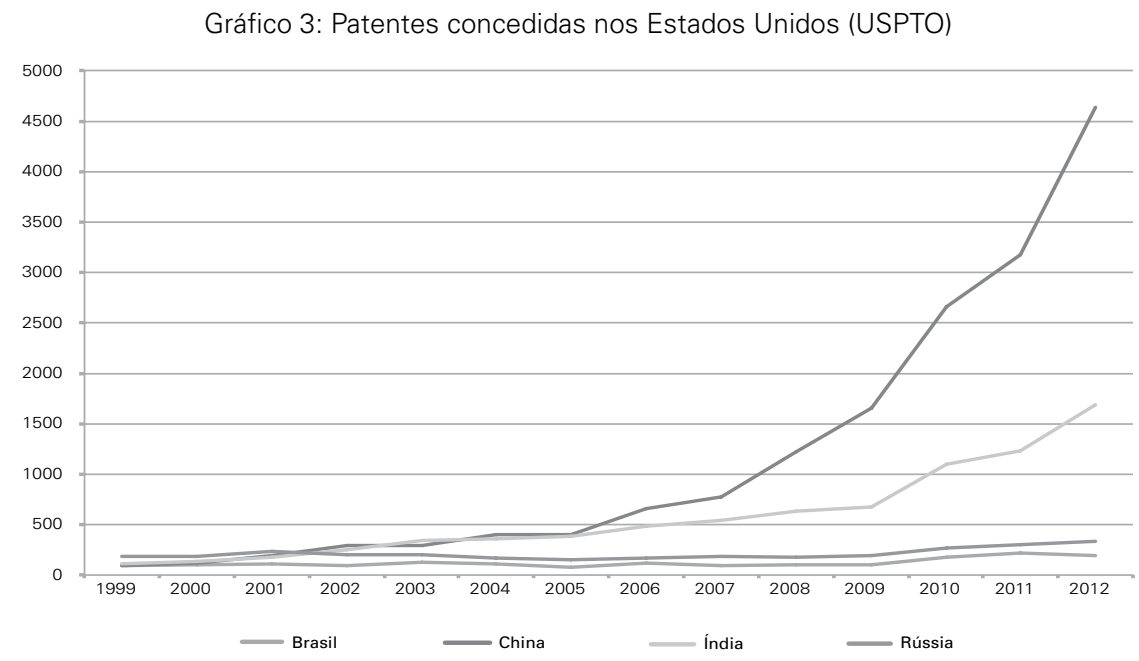

Fonte: Brasil. Ministério da Ciência e Tecnologia, 2010.

Se há consenso sobre o papel da ciência e da pesquisa para a inovação, o grande desafio esta relacionado com a institucionalização e gestão desses processos, havendo hoje múltiplos instrumentos e arranjos, a exemplo das incubadoras, dos parques tecnológicos, dos núcleos de inovação tecnológica nas universidades, entre outros. Em função disso, a ação pública passou a ser orientada para suportar e induzir esses processos (Lundvall, 1992; Alburquerque \& Suzigan, 2011; Diniz et al., 2006).

\section{CIÊNCIA, TECNOLOGIA E INOVAÇÃO: MOTORES DO DESENVOLVIMENTO ECONÔMICO, DO PODER MILIAR E DA ORDEM GLOBAL}

O papel da ciência e da tecnologia nos processos inovativos é tema recorrente na literatura econômica, desde os clássicos. No entanto, foi Schumpeter (1911) quem introduziu de forma sistemática o conceito de inovação como o elemento central na dinâmica capitalista. Ele parte da concepção de fluxo circular, que na prática seria um sistema de reprodução simples, o qual é rompido pelo processo de 
inovação, gerando desequilíbrio, crescimento econômico e ciclo. Para ele, a inovação, motivada pela busca de lucro, se dá de forma combinada ou alternativa de cinco formas: novo bem, novo método, novo mercado, nova fonte de matéria-prima ou novas formas de organização. Em sua obra original, o autor entendia que a inovação era criada por um inovador isolado que a transferia para um empresário inovador capaz de introduzi-la no processo produtivo. A inovação era, portanto, tratada como elemento exógeno. Mais tarde, ao retomar a análise do papel da inovação no desenvolvimento, Schumpeter (1939) demonstrou que no capitalismo consolidado ou oligopolizado, o processo de pesquisa e desenvolvimento que suporta os processos de inovação são desenvolvidos dentro das próprias empresas. Nesse mesmo livro, Schumpeter propõe e analisa uma versão mais acabada dos ciclos econômicos, incorporando a concepção de "ondas longas" proposta originalmente por Kondratieff (1926). Em sua obra Capitalismo, socialismo e democracia Schumpeter (1943) desenvolveu o conceito de "destruição criadora", demonstrando que o processo de inovação é, ao mesmo tempo, o de criação do novo e destruição do velho.

Freeman e Louçã (2001), em As time goes by retomam o debate acerca das ondas longas no capitalismo mundial, resgatando de forma bastante abrangente a discussão histórica e teórica no âmbito da ciência econômica e fazendo uma revisão acerca da importância e das contribuições posteriores dos trabalhos seminais de Kondratieff e Schumpeter, sistematizando e sintetizando os grandes ciclos. O primeiro Kondratieff (1789-1849) é caracterizado pela generalização de inovações na indústria têxtil, pelo uso do ferro e do vapor enquanto força motriz das máquinas. O segundo Kondratieff (1849-1896) é caracterizado pela introdução e generalização da estrada de ferro, tendo como elementos centrais o ferro e o carvão. $\mathrm{O}$ terceiro Kondratieff (1896-1940) é caracterizado pela ascensão do aço, da eletricidade e da indústria química. O quarto Kondratieff tem início durante a II guerra-mundial e dura até por volta de 1990. É caracterizado pela era do petróleo, dos automóveis, da produção e consumo de massa, ou seja, da generalização do padrão fordista de produção, pela expansão do investimento estrangeiro e das empresas multinacionais. O quinto Kondratieff tem início com a difusão das tecnologias da informação e comunicação, e o uso generalizado dos computadores pessoais no final da década de 1980 e início dos anos 1990.

No nosso entendimento, o sexto Kondratieff está sendo constituído. Ao contrário dos ciclos longos anteriores, caracterizados por um cluster de inovações lideradas por um único setor ou conjunto de setores, o próximo Kondratieff será caracterizado por múltiplas trajetórias tecnológicas, dentre elas o aperfeiçoamento das tecnologias da informação e comunicações (TICs), o avanço e a generalização do uso da nanotecnologia, em diferentes aplicações, da biotecnologia e da engenharia genética, de novos paradigmas e trajetórias energéticas, com a emergência de outras fontes de energia (luz solar, energia eólica, hidroenergia marítima, fusão nuclear, hidrogênio).

A maioria dessas novas trajetórias e tecnologias decorre da contribuição interdisciplinar e do cruzamento dessas tecnologias, gerando um processo de integração 
crescente entre áreas de conhecimento e processos produtivos. Portanto, todos esses elementos indicam que o novo ciclo terá características diferentes dos anteriores, combinando a integração crescente das dimensões cientificas, tecnológicas, humanas e ambientais, cujas consequências, boas ou más para a humanidade, são de difícil previsão.

Embora em períodos recentes o desenvolvimento econômico, as novas tecnologias e os processos de inovação estejam totalmente articulados com o desenvolvimento científico, falta prevalência dos objetivos sociais e humanos no processo de desenvolvimento. Segundo Martins (2012), vem ocorrendo um gnosticismo tecnológico, transformando o avanço científico e tecnológico num fim em si mesmo, e não em instrumento para a construção de uma sociedade mais justa, mais humana e ambientalmente sustentável.

\section{A INSERÇÃO DO BRASIL}

\section{Posição relativa e a inserção regional da América Latina}

É dentro do cenário de grandes transformações na economia mundial que se deve pensar as possibilidades da América Latina e do Brasil. No entanto, América Latina é mais uma concepção histórica e cultural. O México e os países da América Central estão fortemente vinculados aos Estados Unidos. Nesse sentido, pensar a integração regional do Brasil é pensar principalmente a integração com a América do Sul.

Apesar das mudanças observadas na distribuição do poder mundial nos últimos anos, a posição da América Latina continua muito limitada. Os três países latino-americanos que compõem o G20 (Argentina, Brasil e México), embora com condições diferenciadas, possuem base econômica, tecnológica e dinâmica econômica relativamente limitadas, comparativamente ao desenvolvimento de outros países, especialmente dos asiáticos.

Além de sua fragilidade econômica, científica e tecnológica, um dos elementos de fragilidade da região é sua pequena integração intrarregional. O clássico diagnóstico de Prebisch (2000[1949]) e de vários outros autores sobre o atraso relativo da América Latina tinha, entre seus argumentos, a pequena integração regional, a má distribuição da renda e a restrição da demanda (Furtado, 1969). Apesar das várias tentativas feitas nas décadas que se seguiram à II Guerra, com a criação da ALALC, ALADI, MERCOSUL, GRUPO ANDINO, os resultados alcançados são muito pequenos em comparação com outros processos de integração regional, a exemplo do NAFTA, EU e ASEAN. No caso do MERCOSUL, atualmente o bloco constitui um entrave aos países-membros para a negociação de acordos de comércio bilaterais, o que tem restringido o crescimento econômico e o desenvolvimento tecnológico.

Tomado o comércio internacional dos grandes blocos econômicos, observa-se 
que a maioria deles possui uma forte integração intrarregional, o que funciona como protecionismo regional. No caso da União Europeia, em 2010, 71\% do comércio internacional dos países que a compõem ocorreu intrabloco. No caso do NAFTA, na América do Norte, composto por apenas três países (EUA, Canadá e México), 49\% do comércio internacional destes se deu entre os mesmos. Fato significativo é o caso asiático. Embora o Japão, a Coreia do Sul, Taiwan, Hong Kong e China sejam verdadeiras máquinas de exportação, $53 \%$ do comércio internacional da região foi efetuado internamente no continente.

Em contraste, na América Latina, apenas $26 \%$ do seu comércio internacional se faz dentro do próprio bloco. Além da pequena complementaridade produtiva, há um grande obstáculo para a integração territorial da própria região, pelo relativamente vazio populacional no interior da América do Sul e pela deficiência do sistema de transportes. No caso do México, este possui uma forte integração com os Estados Unidos, facilitado pela proximidade geográfica. Os pequenos países da América Central funcionam como países primário-exportadores, fortemente dependentes da dinâmica das economias avançadas. No caso da América do Sul, enquanto país como o Brasil possui escala e uma relativa tradição de global trader, países de menor escala encontram grande dificuldade de se integrarem ao comércio internacional inter-regional. Embora o Chile tenha sido aceito como membro da OECD e tenha uma integração internacional muito maior que a dos demais países da região, ele continua exportador de produtos primários e com uma estrutura social interna com grandes desigualdades.

A industrialização desses países se fez com forte presença de empresas estrangeiras, as quais não internalizaram seus esforços de pesquisa, desenvolvimento e inovação nas indústrias aqui instaladas. Isso limitou e limita a capacidade de geração de capacitação tecnológica e de processos inovativos que assegurem capacidade de competição nos mercados globais e integração produtiva entre os mesmos.

Essas características se contrastam fortemente com os modelos e padrões asiáticos. Inicialmente o Japão e, posteriormente, a Coreia do Sul se industrializaram em empresas nacionais, onde o principal ativo era o conhecimento (Amsden, 1989). Mais recentemente os demais países asiáticos e a China seguiram padrões semelhantes. Para Amsden os países asiáticos seriam classificados como independentes, por geraram seu próprio desenvolvimento tecnológico, e os países da América Latina como integracionistas, por comprarem tecnologia. Embora a industrialização chinesa conte com a presença de empresas multinacionais, estas agem sob o absoluto controle do governo, sendo obrigadas a internalizar o esforço de pesquisa. Adicionalmente, o sistema acadêmico universitário asiático, que vem sendo desenvolvido de forma acelerada, está totalmente orientado para servir de suporte à formação de recursos humanos e à pesquisa, visando atender ao sistema produtivo. Sistema produtivo este que tem como objetivos o crescimento, a modernização e a inovação, com vistas ao ganho de competitividade dos mercados globais. De forma diferente, mas com propósitos semelhantes, a Rússia tem buscado retomar 
seu esforço de pesquisa para modernização produtiva de forma acelerada, com vistas a recuperar seu poder na geopolítica mundial (Mazat \& Serrano, 2011).

A integração da América Latina, seu catching up tecnológico e a melhoria na distribuição de renda constituem o caminho necessário e inevitável para o fortalecimento regional, inclusive como estratégia geopolítica para a integração no espaço mundial e como mecanismo de preservação das condições de paz da própria região. Entretanto, este é um grande desafio, à luz de diferenças políticas e econômicas na região, com governos que oscilaram nos últimos 20 anos entre diferentes diretrizes e orientações ideológicas e de políticas econômicas.

\section{Potencialidades e desafios estruturais do Brasil}

Tomado o caso do Brasil, observa-se que o país possuía, em termos mundiais no ano de 2011, 6,3\% da área geográfica, 2,2\% do PIB, 2,8\% da população, 2,7\% da produção científica, mas apenas 1,3\% das exportações. No período 2000-2011, sua economia cresceu à taxa média anual de 3,9\%, contra a média mundial de $2,8 \%$, o que foi insuficiente para que a participação brasileira no PIB e nas exportações globais aumentasse de forma significativa. Apesar da crise conjuntural, com drástica redução na taxa de crescimento no ano de 2012, o país possui grandes potencialidades para ampliar seu ritmo de expansão, tanto no comércio internacional quanto no mercado interno. Nesse sentido, serão listadas a seguir as potencialidades e os desafios estruturais para a economia e a sociedade brasileiras:

\section{Potencialidades}

a) Área geográfica e recursos naturais

O Brasil possui uma área geográfica de 8,5 milhões de $\mathrm{km}^{2}$, acrescida de aproximadamente 4,5 milhões de $\mathrm{km}^{2}$ de plataforma marítima, constituída pela chamada Amazônia azul.

b) Tamanho e características de sua população

Com 200 milhões de habitantes, o país possui escala para ampliar seu peso econômico e o crescimento de seu mercado interno.

c) Uniformidade linguística e identidade cultural

d) Bônus demográfico

Tendo em vista as altas taxas de crescimento populacional das décadas anteriores e a queda recente e acentuada dessas taxas, o Brasil possui hoje um grande percentual de sua população em idade ativa, o que significa uma vantagem contemporânea, denominada pelos demógrafos como "bônus demográfico".

a) Base produtiva

Embora muito heterogênea, o país possui uma estrutura produtiva diversificada em todos os setores.

b) Avanço científico recente

Embora ainda esteja na $13^{a}$ posição no ranking mundial de produção científica, 
o país vem avançando de forma acelerada. O país vem progredindo significativamente na sua produção científica e na qualificação de recursos humanos. O grande desafio é o de criar condições técnicas, institucionais e políticas para a transformação desse conhecimento científico em conhecimento técnico e tecnológico, com a sua aplicação para a inovação econômica e social. Um elemento central está relacionado com o peso da base produtiva estrangeira e a necessidade de que esta seja estimulada a internalizar no país seu esforço de pesquisa e desenvolvimento.

c) Ambiente de paz com os vizinhos territoriais

d) Estabilidade política e institucional

Não há no cenário brasileiro indício de ruptura de sua estabilidade político-institucional, embora a melhoria e o avanço de sua institucionalidade pública precisam ser aperfeiçoados, especialmente no combate à corrupção.

\section{Desafios}

a) Baixa escolaridade fundamental e média

Esta é, a nosso ver, a questão mais grave para o desenvolvimento brasileiro. Além da deficiência na formação de recursos humanos, a baixa escolaridade contribui para a baixa produtividade da economia brasileira, para a baixa consciência política e social de parcela expressiva da população. Por outro lado, a baixa escolaridade fundamental e média traz graves consequências para a qualificação profissional de seus recursos humanos, e como preparação para o ensino superior. Este, por sua vez, é a condição decisiva para o avanço científico e tecnológico como base para o desenvolvimento econômico e social do país.

b) Debilidade do Departamento I da economia

Qualquer processo de investimentos, progresso técnico e inovações têm uma forte dependência do Departamento I da economia, produtor dos bens de produção.

c) Debilidade do planejamento estatal

O país precisa retomar sua capacidade de realizar um planejamento de curto, médio e longo prazos e pensar em políticas de Estado. A incapacidade de articular o planejamento faz com que o gestor público atue quase que de forma pontual resolvendo problemas emergenciais aqui e acolá e de forma desarticulada, sem uma definição clara de objetivos, metas, meios e visão estratégica.

d) Monolinguíssimo

Embora, por um lado, seja bom que toda a população brasileira fale a mesma língua, por outro lado, a integração mundial exige que sua população desenvolva habilidades em outras línguas, especialmente em inglês, que se transformou na língua franca mundial.

e) Entraves institucionais e burocráticos

As instituições públicas brasileiras precisam avançar de forma a serem mais eficientes no uso do dinheiro público, todavia reduzindo o excessivo volume de normas que muitas vezes engessam e encarecem o gasto público produzindo dis- 
torções e impedindo avanços estruturais do país. Nesse sentido é necessário repensar as funções e o papel do Estado brasileiro.

f) Baixa integração das instituições e da comunidade científica com as atividades produtivas de bens e serviços

Os modernos processos de inovação tecnológica estão fundamentados nos avanços científicos. No capitalismo, a maior parcela da produção e das inovações é feita pelas empresas privadas. Nesse sentido, preservada a natureza pública das universidades, é necessário construir caminhos que permitam uma maior integração entre as universidades e o sistema empresarial e produtivo.

g) Desigualdade social

O Brasil é um país com os maiores níveis de desigualdade social. Além da justiça social, a redução da desigualdade é condição para a melhoria do sistema educacional, para a tomada de consciência política e social, e, consequentemente, para o desenvolvimento do país.

h) Rápida concentração urbana

A população brasileira se multiplicou por quatro nos últimos sessenta anos. Simultaneamente ocorreu um forte processo de urbanização, tendo o grau de urbanização subido de $36 \%$ em 1950 para $83 \%$ em 2010. Além de um processo migratório bastante significativo que impactou a ocupação do território brasileiro. O crescimento das regiões metropolitanas representa um desafio para a política pública brasileira, principalmente no que tange à infraestrutura e aos equipamentos urbanos.

i) A deficiência da infraestrutura em geral, especialmente transportes

A deficiência da infraestrutura se manifesta de forma mais aguda no sistema viário e dos portos, além do problema do congestionamento urbano. O país fez uma opção rodoviária, mas não possui uma rede de estradas em condições de facilitar a integração.

Considerada a grande dimensão territorial do país, a deficiência do sistema de transportes dificulta e encarece a integração comercial e sobrecarrega o custo das exportações, o que se soma à deficiência do sistema portuário e gera o chamado "custo Brasil".

\section{EDUCAÇÃO, CIÊNCIA, TECNOLOGIA E INOVAÇÃO COMO IMPERATIVOS PARA O DESENVOLVIMENTO BRASILEIRO}

Sem negar a importância das potencialidades e dos desafios para o desenvolvimento brasileiro antes listados, cabe destacar o papel central da educação, da ciência, da tecnologia e da inovação para o desenvolvimento econômico e social do país.

Em primeiro lugar, entende-se como requisito central para o desenvolvimento do país e para a implantação de um sistema nacional de inovação, o fortalecimento da educação básica (fundamental e média). Esta tem como função a preparação 
das crianças e dos jovens brasileiros em sua escolaridade linguística, matemática, científica e de conhecimentos e cultura gerais, para sua formação cidadã, capacitação profissional e preparação para os estudos universitários.

Se há consenso político e social sobre esses objetivos, não há definições claras dos meios e das metas para a sua consecução. Entre as principais ações para a construção de um sistema escolar básico, público e de qualidade, listaríamos quatro: capacitação e reconhecimento social e financeiro do professor; introdução da escola em tempo integral; complemento e melhoria da infraestrutura, e adequação e acompanhamento permanente dos currículos.

Entende-se que uma profunda reestruturação do sistema educacional brasileiro em seu nível inicial é condição fundamental para um projeto de desenvolvimento nacional que tenha como objetivo central a construção de um país mais rico, mais justo, mais harmônico e mais solidário, em um ambiente de paz interna e internacional e capaz de cooperar com outros povos e nações.

Partindo da concepção de um sistema público e universal, a primeira condição é a redefinição de atribuições das três instâncias de governo e da complementaridade entre as mesmas. Isso implica uma nova concertação do pacto federativo com vistas à reconfiguração de responsabilidades, dos meios, da forma de financiamento, das metas e dos caminhos alternativos e das reformulações estratégicas para a sua consecução.

A reestruturação, o aprimoramento e a implementação do sistema de educação básica compõem a primeira etapa para a construção dos meios necessários a uma sociedade do conhecimento, baseada na ciência, na tecnologia e na inovação. A base científica e seu avanço contínuo e permanente conformam, portanto, a condição estrutural para o desenvolvimento, para a modernização produtiva, para a liderança econômica e política e para a competição nos mercados doméstico e internacional.

A experiência histórica demonstra que os países que lideraram a produção e aplicação do conhecimento científico e tecnológico lideraram também o crescimento econômico e os padrões culturais e políticos entre os países e os povos.

Após a II Guerra Mundial, o atrelamento entre o sistema acadêmico-universitário e o sistema empresarial tornou-se mais forte. O conhecimento científico passou a ser o maior instrumento para a criação de novas empresas ou novos empreendimentos, cujo maior destaque é o Vale do Silício e a Estrada 128 na região de Boston, ambas nos Estados Unidos (Saxenian, 1994). Essas experiências foram generalizadas nos Estados Unidos e assimiladas em vários países da Europa e da Ásia. A partir das experiências americanas, foram criadas várias cidades científicas, a exemplo de Tsukuba, no Japão; Taedok, na Coreia do Sul, e Novosibirsk, na Rússia. À luz dessas iniciativas, vários estudiosos passaram a analisar a constituição dos chamados sistemas institucionais de inovação, alguns de forma planejada e outros de forma espontânea (Lundvall, 1992). Os agentes públicos e privados passaram a buscar o planejamento dessas ações, criando instrumentos e articulações entre si com vistas a estimular e potencializar os processos de inovação. Foram criadas, na maioria dos países, instâncias institucionais para promover e estimular 
a interação de universidades, centros de pesquisa e sistema empresarial a fim de fortalecer os sistemas nacionais, regionais ou locais de inovação (Braczyk et al., 1998; Diniz et al., 2006).

O Brasil chegou atrasado ao processo. Segundo Cano (1993), as primeiras indústrias têxteis só foram instaladas no Brasil aproximadamente 100 anos após a Revolução Industrial inglesa, tendo os demais setores industriais sido instalados também com grande atraso. As primeiras instituições de ensino superior somente foram criadas na segunda metade do século XIX e as primeiras universidades somente no século XX.

Mesmo assim, o país tem conseguido avançar em várias frentes. Do ponto de vista produtivo, embora ainda muito heterogêneo, há vários setores modernos que têm conseguido fazer seus alcances tecnológicos (catching up). São exemplos a indústria aeronáutica, que consegue competir no mercado mundial de aviões médios; a Petrobras, com sua liderança na exploração de petróleo em águas profundas; o setor agropecuário, com alta produtividade, competindo no mercado mundial como um dos grandes exportadores de commodities agrícolas; o setor serviço, com segmentos robustos, a exemplo do sistema bancário. Do ponto de vista do seu sistema acadêmico universitário, o crescimento do número de artigos científicos publicados, o número de patentes depositadas e a posição de várias universidades brasileiras nos rankings internacionais são indicadores do avanço da posição do país no contexto mundial. Além do sistema universitário público, o Brasil fez um grande esforço institucional e político, com destaque para a criação de vários centros federais de fomento à pesquisa ou especializados em alguns setores. Entre estes, cabe ressaltar o CNPQ, a CAPES, a FINEP, o Ministério da Ciência, Tecnologia e Inovação (MCTI), o ITA, o CTA, o INPE, a FIOCRUZ, o INPA, o Laboratório de Luz Síncrotrone a EMBRAPA. Mais recentemente, a partir da pioneira FAPESP, foram criadas fundações de apoio à pesquisa pelos estados federados, as denominadas FAPs. Desse modo, embora relativamente atrasado em relação ao mundo, o governo brasileiro montou um sofisticado e ativo sistema institucional de apoio à ciência e à tecnologia, que, todavia, necessita de tempo para seu amadurecimento e aperfeiçoamento.

Apesar de todo esse aparato, há alguns pontos falhos que precisam ser aperfeiçoados, de forma a se obter melhores resultados do esforço de ensino e pesquisa e sua materialização na modernização produtiva. Entre estes, cabe destacar:

a) Reestruturação do sistema acadêmico universitário;

b) Novo marco regulatório do sistema de ciência e tecnologia;

c) Articular a política de ciência e tecnologia com as políticas macroeconômicas, industriais e de comércio exterior;

d) Ampliação do esforço de pesquisa pelo setor empresarial: enquanto nos países desenvolvidos, na China e na Coreia do Sul o gasto privado em pesquisa e desenvolvimento gira em torno de $70 \%$ do total, no Brasil, o gasto do setor empresarial ainda não alcança $50 \%$.

A Estratégia Nacional de Ciência Tecnologia e Inovação para o período 2012-2015 (ENCTI, 2011), publicada pelo MCTI, define as linhas gerais da política 
brasileira. Parte da concepção ou definição de que ciência, tecnologia e inovação constituem um dos eixos estruturantes do desenvolvimento brasileiro. Identifica os desafios para superar a defasagem tecnológica do Brasil, para alcançar liderança internacional, para a sustentabilidade e desenvolvimento de economia de baixo carbono e para alcançar objetivos sociais de superação da pobreza e das desigualdades. Discute, também, os meios e os caminhos para viabilizar o financiamento, fazer a promoção empresarial, construir e manter a infraestrutura de pesquisa, capacitar os recursos humanos, aperfeiçoar o marco legal e estimular os arranjos institucionais facilitando a ponte entre a pesquisa e sua utilização.

A Estratégia define um conjunto de setores como prioritários para o desenvolvimento brasileiro, a saber: Tecnologias da Informação e das Comunicações; Fármacos e Complexo Industrial da Saúde; Petróleo e Gás; Complexo Industrial da Defesa, Aeroespacial, Nuclear, Biotecnologia, Nanotecnologia, Biodiversidade, $\mathrm{Mu}-$ danças Climáticas, Energia Renovável, Oceanos e Zonas Costeiras, Cidades Sustentáveis. No entanto, a Estratégia não define com clareza os objetivos prioritários, não quantifica os meios e as metas, não indica os diferentes caminhos estratégicos e, a partir de uma avaliação crítica, a escolha de alternativas.

\section{À GUISA DE CONCLUSÕES}

Como demonstrado ao longo do texto, a estrutura de poder mundial se baseia em quatro pilares básicos e articulados entre si, a saber: controle do território, sistema de segurança, capacidade de produção, força da moeda e das finanças internacionais e conhecimento (ciência, tecnologia e inovação)

Após a II Guerra Mundial o poder mundial foi estruturado em torno de dois blocos. Um liderado pelos Estados Unidos e o outro pela União Soviética, dos quais decorreu a guerra fria. Após um período de sucesso de ambos, os dois blocos entraram em crise, como analisado na segunda seção deste trabalho.

Ao lado das crises dos sistemas centrais, vem ocorrendo grande crescimento econômico dos países periféricos, especialmente da China. Essas mudanças na geografia econômica poderão trazer também mudanças na geografia política. Em um mundo com grandes mudanças econômicas e tecnológicas e em crescente competição, são abertas janelas e oportunidades para que novos países assumam papel de destaque na nova ordem econômica e política mundial. A esse respeito, embora ainda tímida, a governança mundial exige a presença de novos atores, como retrata a passagem do G6 para G7, G8 e, agora, G20. A perda de importância relativa da então União Soviética, dos Estados Unidos, do Japão e da União Europeia se conjuga com o crescimento da importância de outros países, com destaque para a China e a Índia ou dos países que compõem o acrônimo BRICS. Ressalte-se ainda a importância da África, por possuir 1 bilhão de habitantes, 30 milhões de km² e abundância de recursos.

É diante desse cenário que se deve pensar a posição relativa e as formas de inserção do Brasil. Ao lado de suas potencialidades, há que ressaltar os grandes 
obstáculos e desafios que precisam ser superados. Destacam-se as grandes desigualdades sociais, a baixa qualidade da educação fundamental e média, a rápida concentração urbana sem a adequada oferta de infraestrutura e serviços, a debilidade do Departamento I e as deficiências da infraestrutura. Um elemento central é a necessidade de se pensar projeto de nação e de se definir com alguma clareza o papel do Estado no processo de desenvolvimento, inclusive com a urgente necessidade de reforma do Estado brasileiro. Para a superação desses desafios, enfatiza-se o papel central da educação, da ciência e da tecnologia como instrumentos básicos para um processo de desenvolvimento que seja capaz de combinar crescimento econômico e justiça social com uma inserção internacional que considere nossa competição com os países desenvolvidos e nossa solidariedade com os países do Sul, especialmente os da África e da América Latina.

\section{REFERÊNCIAS BIBLIOGRÁFICAS}

Albuquerque, E. M; Suzigan, W., orgs. (2011) Em busca da inovação: interação universidade-empresa no Brasil. Belo Horizonte: Autêntica Editora, 2011. v. 1.

Amsden, A. H. (2009) A ascensão do "resto": os desafios ao Ocidente de economias com industrialização tardia. São Paulo: Unesp.

Amsden, A. H. (1989) Asia's next giant: South Korea and late industrialization. Oxford: Oxford University Press.

Bleaney, M. (1985) The rise and fall of Keynesian economics: an investigation of its contribution to capitalist development. Reino Unido: Macmillan Education.

Bresser-Pereira, L. C. (2011) "Structuralist macroeconomics and new developmentalist”, São Paulo, FGV: Texto para Discussão No 298.

Bresser-Pereira, L. C., org. (2012) Depois da crise: a China no centro do mundo? Rio de Janeiro: Editora FGV, 2012.

Brown, A. (2011) Ascensão e queda do comunismo. Rio de Janeiro: Record.

Brzezinski, Z. (1986) EUA-URSS: o grande desafio. Rio de Janeiro: Nórdica.

Cano, W. (1993) Reflexões sobre o Brasil e a nova (des)ordem internacional. Campinas: Editora da Unicamp.

Churchill. W. (1946) Discurso proferido no Westminster College. Fulton, Estados Unidos.

Costa, W. M. (2005) Política e território em tempos de mudanças globais. São Paulo: Tese (Livre-Docência), FFLCH/USP:

Costa, W. M. (2008) Geografia Politica e Geopolítica. São Paulo: EDUSP.

Diniz, C.C. e Gonçalves, E. (2005) “Economia do conhecimento e desenvolvimento regional no Brasil”, in Diniz, C. C. e Lemos. M.B. Economia e Território. Belo Horizonte: Editora UFMG.

Diniz, C. C. et al.(2006) "Conhecimento, inovação e desenvolvimento regional/local”, in Diniz, C.C. \&Crocco, M. Economia Regional e Urbana: contribuições teóricas recentes. Belo Horizonte: Editora UFMG.

Diniz, C. C. e Razavi, M. (1999) “São José dos Campos and Campinas: state anchored dynamos”, in Markusen, A. et al. Second tier cities: rapid growth beyond the metropolis. Minneapolis: University Minnesota Press.

Diniz, C. C. e Santos, F.G.T. (1999) “Manaus: vulnerability in a satellite platform”, in Markusen, A. et al. Second tier cities: rapid growth beyond the metropolis. Minneapolis: University Minnesota Press.

Dosi, G et al. (1992) Technical change and economic theory. Londres/Nova York: Pinter Publishers. 
Ferrari, M. A. R.; Freitas, F. N. P.; Barbosa Filho, N. (2013) "A taxa de câmbio real e a restrição externa: uma proposta de releitura com elasticidades endógenas”, Revista de Economia Política 33 (1).

Freeman, C. (1982) The economics of industrial innovation. Londres: Frances Printer.

Freeman, C e Louçã, F. (2001) As time goes by: from the industrial revolutions to the information revolution. Oxford: Oxford University Press.

Frieden, J. A. (2006) Global capitalism: Its fall and rise in the twentieth century. Nova York: WW Norton.

Fukuyama, F. (1989) "The end of history”, The National Interest, vol. 16, Summer

Furtado, C. (2007 [1969]) A economia latino-americana: formação histórica e problemas contemporâneos. São Paulo: Companhia das Letras.

Gilpin, R. (2001) Global political economy. Princeton: Princeton University Press.

Helleiner, E. (1994) States and the reemergence of global finance: from Bretton Woods to global finance. Ithaca: Cornell University Press.

Hirsch, J. (2010) Teoria materialista do Estado: processos de transformação do sistema capitalista de Estados. Rio de Janeiro: Revan.

Hobsbawm, E. (1995) A era dos extremos: o breve século XX (1914-1991). São Paulo: Companhia das Letras.

Hymer, S. (1978) Empresas multinacionais: a internacionalização do capital. Rio de Janeiro: Graal.

Kondratieff, N. D. (1935) "The long waves in economic life." The Review of Economic Statistics, vol. XVII, $n^{\circ}$ 6, novembro.

Krugman, P. e Taylor, L. (1978). "Contractionary Effects of Devaluation”. Journal of International Economics, 8(3): 445-456.

Lundvall, B-A. (1992) National systems of innovation. Londres: Pinter.

Mackinder, H. J. (1904) “The geographical pivot of history”. The Geographical Journal, vol. XXIII.

Mackinder, H. J. (1943) "The round world and the winning of the peace". Foreing Affairs, vol. 21.

Mandel, E. (1982) O capitalismo tardio. São Paulo: Abril Cultural.

Martins, H. (2011) Experimentum Humanum: CivilizaçãoTecnológica e Condição Humana. Lisboa: Relógio D’Água Editores.

Massey, D. e Meegan, R. (1982) The anatomy of job loss: the how, why and where of employment decline. Londres: Methuen.

Mazat, N. e SERRANO, F. (2012) "A geopolítica da federação russa em relação aos Estados Unidos e à Europa: vulnerabilidade, cooperação e conflito". In: Alves, A. G. M. P. O renascimento de uma potência? A Rússia no século XXI. Brasília: IPEA.

Missio, F; Oreiro, J. L; Jayme Jr. F. G. (2010) “Câmbio, crescimento e heterogeneidade produtiva num modelo keynesiano-estruturalista”. Texto para Discussão 413, UFMG/Cedeplar.

Moraes, A. C. R. (1990) Ratzel: geografia. São Paulo: Ática.

Nelson, R. R. (2006) As fontes do crescimento econômico. Campinas: Editora da Unicamp.

Nye, J. (2006) Soft Power: the means to success in world politics. Nova York: PublicAffairs.

O’Neill, J. (2012) O mapa do crescimento: oportunidades econômicas nos BRICS e além deles. São Paulo: Globo.

Peet, R. (1983). "Relations of production and relocation of United States manufacturing industry since 1960”. Economic geography, vol. 59, n 2, abril.

Perez, C. and Soete, L. (1988) "Catching up in technology: entry barriers and windows of opportunity", in Dosi et al. Technical Change and economic theory, London, Pinter/

Piore, M. e Sabel, C.(1984) The second industrial divide: possibility. Nova York: Basic Books.

Prebisch, R. (2000) "O desenvolvimento econômico da América Latina e alguns de seus problemas principais” in: Bielschowsky, R. (org.) Cinquenta anos de pensamento na Cepal. Rio de Janeiro: Record.

Raffestin, C. ([1980] 1993) Por uma geografia do poder. São Paulo: Editora Ática.

Rodrik, D., (2007). "Real Exchange Rate and Economic Growth: Theory and Evidence”, John F. Kennedy School of Government, Harvard University, Draft, July. 
Rosenberg, N. e Birdzell Jr., L. E. (1986) A história da riqueza do ocidente: a transformação econômica do mundo industrial. Rio de Janeiro: Record.

Saxenian, A. (1994) Regional advantage: culture and competition in Silicon Valley and Route 128. Cambridge: Harvard University Press.

Schumpeter, J. A. (1984) Capitalismo, socialismo e democracia. Rio de Janeiro: Editora Zahar.

Schumpeter, J. A. (1964) Business Cycles: a theoretical, historical and statistical analysis of the capitalist process. Nova York: McGraw-Hill, 1964.

Schumpeter, J. A. (1982) Teoria do Desenvolvimento Econômico. São Paulo: Abril Cultural.

Spykman, N. (1953) Os Estados Unidos Frente ao Mundo. Nova York.

Strange, S. (1996) States and markets. Londres: Continuum.

Thirlwall, A. P. (1979) "The Balance of Payments Constraint as an Explanation of International Growth Rate Differences”, Banca Nazionale del Lavoro Quarterly Review, no 128, March. 